\title{
USO DA BORRA DE FOSFATO COMO FONTE DE FÓSFORO PARA AGRICULTURA, A PARTIR DA SOLUBILIZAÇÃO DE P POR BACTÉRIAS ACIDÓFILAS.
}

Júlia Pimenta Pereira - juliapimentap@gmail.com

Faculdade Santo Agostinho - Campus Sete Lagoas

Fernando Augusto Moreira - fernando.moreira@unifemm.edu.br Centro de Desenvolvimento da Tecnologia Nuclear - CDTN

Rochel Montero Lago - rochellago@gmail.com

Departamento de Química - UFMG

Ivanildo Evódio Marriel - ivanildo.marriel@embrapa.br

Embrapa Milho e Sorgo

Francisco Adriano de Souza - francisco.adriano@embrapa.br

Embrapa Milho e Sorgo 


\section{RESUMO}

O Brasil é o terceiro maior produtor agrícola e quarto maior consumidor de fertilizantes do mundo. Até 2025, o Brasil terá que importar 82, 80 e 95\%, respectivamente, de fertilizantes a base de NPK para suprir sua demanda nacional. Neste sentido, a busca por novas fontes de nutrientes para a agricultura constitui uma das estratégias para diminuir a dependência externa por fertilizantes. Dentre os maiores desafios da crescente industrialização, destacam-se a geração e a destinação ou disposição dos resíduos e efluentes industriais. Porém, diversos processos industriais geram resíduos com potencial de uso agrícola, como fertilizantes e ou corretivos de solo, minimizando assim impactos ambientais e contribuindo para uma agricultura mais sustentável. O objetivo deste trabalho preliminar foi verificar o potencial da utilização do resíduo borra de fosfato como fonte alternativa de fósforo a partir ação de bactérias acidófilas. O estudo envolveu etapas de amostragem, isolamento, genotipagem e identificação molecular das estirpes isoladas. Posteriormente foi conduzido bioensaio de solubilização do fósforo presente no resíduo borra de fosfato, na presença e ausência de enxofre elementar por três bactérias acidófilas. Os resultados mostraram que a estratégia de isolamento adotada permitiu a obtenção de 48 estirpes de bactérias acidófilas pertencentes a Proteobactérias dos gêneros Acidocella, Achromobacteria, Bacillus, Burkholderia, Fictibacillus, Halothiobacillus, Pandoraea e Thiomonas.. A solubilização de $\mathrm{P}$ foi eficiente por uma das estirpes, que possibilitou aumento de $28,6 \%$ da solubilidade de $\mathrm{P}$ contido no resíduo borra de fosfato.

Palavras-chave: fertilizantes fosfatados; Acidocella; proteobactéria, resíduo industrial.

\section{INTRODUÇÃO}

O Brasil é o terceiro maior produtor agrícola e quarto maior consumidor de fertilizantes do mundo. Projeções colocam o país como o maior produtor agrícola mundial até 2019 (OCDE-FAO). Para atingir esta estimativa o Brasil terá que importar 82, 80 e 95\%, respectivamente, de fertilizantes a base de NPK para suprir sua demanda até 2025. Este cenário aponta o grande potencial agrícola do país, e também expõe a grande dependência externa de fertilizantes.

Neste sentido a busca por novas fontes de nutrientes para a agricultura constitui uma das estratégias para diminuir a dependência externa por fertilizantes. Diversos processos industriais geram resíduos com potencial de uso agrícola, como fertilizantes e ou corretivos de solo. Quando não destinados corretamente esses resíduos apresentam potencial risco ambiental. A viabilização de um resíduo como fertilizante ou corretivo 
depende da sua composição e da presença de metais pesados entre outros aspectos (PIRES; MATTIAZZO, 2008).

A Borra de Fosfato (BF) é um resíduo da indústria metalomecânica, com elevado teor de fósforo, gerado do processo de fosfatização de superfícies metálicas. Estudos de caracterização realizados por Giffoni \& Lange (2005) demonstram que os principais constituintes da borra são fósforo, ferro, zinco, níquel e sódio e outros elementos essenciais ao crescimento de plantas. A eficiência de um resíduo como fertilizante não depende somente da sua composição, mas principalmente, dos teores disponíveis para as plantas.

Embora a borra de fosfato não seja um resíduo perigoso, seu gerenciamento representa um grave problema ambiental para a indústria, em virtude do alto custo associado transporte, tratamento e disposição final deste resíduo e da falta de espaço físico nas instalações industriais para armazenamento, bem como ausência de informações técnicas por parte das indústrias e funcionários. Para equacionar estes problemas, tornase necessária uma investigação direta com uma avaliação dos resíduos gerados que permita identificar uma tecnologia de tratamento, preferencialmente uma alternativa, com a separação e reutilização dos contaminantes (SIMAS, 2007).

O tratamento de resíduos com microrganismos pode aumentar a disponibilidade de nutrientes para as plantas através de processos de solubilização, como também, reduzir a disponibilidade de elementos tóxicos. Algumas bactérias são capazes de oxidar compostos inorgânicos reduzidos, dentre estes, compostos de enxofre (S) gerando sulfatos, ou seja, produzem naturalmente ácido sulfúrico. O ácido sulfúrico é utilizado na indústria de fertilizantes para produção de ácido fosfórico a partir do ataque de rochas fosfáticas. Diante disso, estes microrganismos podem ser utilizados no desenvolvimento de rotas alternativas para processamento de rochas ou resíduos fosfáticos visando a solubilização de fósforo (HAWKES et al., 2006; GADD, 2010).

A BF é um material com alto teor de fósforo, apresenta baixo conteúdo de impurezas e necessita de uma destinação correta. Neste contexto, o presente trabalho tem como objetivo avaliar a solubilização de $\mathrm{P}$ a partir da ação de bactérias acidófilas sobre a $\mathrm{BF}$ e seu uso como fonte de fósforo para a agricultura, contribuindo de maneira significativa para o desenvolvimento sustentável da agricultura no Brasil. 


\section{METODOLOGIA}

\subsection{Caracterização da borra de fosfato}

O resíduo borra de fosfato foi coletado no processo produtivo de uma empresa que possui como atividade a fabricação de transformadores de potência localizada no município de Contagem, região metropolitana de Belo Horizonte, Minas Gerais. A amostragem foi realizada conforme a norma NBR 10007/04 da ABNT. O resíduo foi caracterizado no Centro de Desenvolvimento da Tecnologia Nuclear (CDTN) por espectroscopia de fluorescência de Raios-X, sendo aplicada para quantificar os elementos constituintes da borra de fosfato e suas concentrações.

\subsection{Cultivo e identificação de microrganismos}

Foram utilizadas amostras de mangue para o isolamento e cultivo de bactérias acidófilas. As amostras foram enriquecidas em meios de cultura seletivos (Thiobacillus Ágar e Thiobacillus acidophilus Ágar), descritos por Starosvetsky et al., 2013, contendo formas reduzidas de enxofre, sob agitação e temperatura de $30^{\circ} \mathrm{C}$ por aproximadamente 7 dias. As amostras enriquecidas foram diluídas e plaqueadas em meios sólidos seletivos contendo indicador de $\mathrm{pH}$ e incubadas a temperatura controlada pelo período de 5 a 7 dias. As colônias foram purificadas através de repicagens periódica e enviadas à Coleção de Culturas de Microrganismos Multifuncionais da Embrapa Milho e Sorgo para a preservação. Os isolados foram submetidos à análise molecular de genotipagem por BOX PCR e sequenciamento de DNA. As sequências foram editadas através do programa CodonCode Aligner (CodonCode Corporation $\left.{ }^{\circledR}\right)$ e comparadas no GenBank pelo programa BLAST N (Basic Local Aligment Search Tool) no National Center for Biotechnology Information - NCBI (ncbi.nlm.nih.gov).

\subsection{Bioensaio para avaliação da solubilização de $P$}

Os isolados foram selecionados, basicamente, a partir de padrões fenotípicos de alteração de $\mathrm{pH}$ do meio de cultura, uma vez que as estirpes ainda não haviam passado pela identificação molecular no início da preparação do bioensaio, sendo selecionadas 3 bactérias. O delineamento experimental foi inteiramente casualizado, em esquema fatorial 4x2: controle negativo (sem adição de microrganismos) e três estirpes de bactérias na ausência e na presença de enxofre elementar. Para a realização do teste, foram adicionados a tubos Falcon de $50 \mathrm{ml} 15 \mathrm{ml}$ do meio de cultura, em triplicata, contendo ou não 0,15 g de enxofre elementar esterilizado por vapor fluente (KIYAN, 1990), 5\% de 
BF $(750 \mu \mathrm{L})$ e o inoculante. Os tubos foram submetidos a agitação $(146 \mathrm{rpm})$ a $30 \pm 2{ }^{\circ} \mathrm{C}$ por aproximadamente 20 dias. Neste ensaio, foi utilizado apenas o meio Thiobacillus acidophilus líquido, que contém em sua formulação $0,5 \mathrm{~g} / \mathrm{L}$ de fosfato monopotássico.

Posteriormente, as amostras foram enviadas ao laboratório de Análise Foliar da Embrapa Milho e Sorgo para a quantificação de fósforo solubilizado. A metodologia segue o Manual de Análises Químicas de solos, plantas e fertilizantes da Embrapa - 2009 (com adaptações). A técnica de detecção utilizada foi a Espectroscopia de Emissão Óptica com Plasma Acoplado Indutivamente (Inductively Coupled Plasma - Optical Emission Spectrometer - ICP OES).

\subsection{Análise estatística}

Os dados obtidos foram submetidos à análise de variância utilizando programa SISVAR. Os tratamentos que apresentaram diferença significativa ao nível de $\leq 5 \%$ pelo bioensaio foram diferenciados pelo Teste de Tukey.

\section{RESULTADOS E DISCUSSÃO}

\subsection{Caracterização da borra de fosfato}

A análise química da amostra de borra de fosfato (método de fluorescência de Raios-X) evidenciou alta concentração de fósforo e a ausência de arsênio, cádmio, chumbo e mercúrio, metais potencialmente tóxicos na agricultura: $\mathrm{P}_{2} \mathrm{O}_{5}, 46,72 \% ; \mathrm{Fe}_{2} \mathrm{O}_{3}$, 31,24\%; $\mathrm{ZnO}, 17,20 \%$; $\mathrm{SiO}_{2}, 3,82 \%$; $\mathrm{CaO}, 0,80 \%$; $\mathrm{NiO}, 0,10 \% ; \mathrm{MnO}, 0,08 \%, \mathrm{~K}_{2} \mathrm{O}$, < 0,01, $\mathrm{SrO},<0,01, \mathrm{SO}_{3}$, não detectado. $\mathrm{O}$ cromo $(\mathrm{Cr})$, um metal tóxico limitante ao uso de resíduos industriais na agricultura, não foi identificado na amostra, assim como demais metais como alumínio e titânio.

$\mathrm{O}$ teor de $\mathrm{P}_{2} \mathrm{O}_{5}$ na $\mathrm{BF}$ está na faixa encontrada no fosfato monoamônico ou MAP (46 a 50\% de $\mathrm{P}_{2} \mathrm{O}_{5}$ ) que é o fertilizante com maior teor de $\mathrm{P}$ no mercado, sendo superior aos demais fertilizantes disponíveis: fosfato diamônico ou DAP (40\% de $\mathrm{P}_{2} \mathrm{O}_{5}$ ), superfosfato simples (16 a 18\% de $\mathrm{P}_{2} \mathrm{O}_{5}$ e 18 a 20\% de Ca - Cálcio), superfosfato triplo (41\% de $\mathrm{P}_{2} \mathrm{O}_{5}$ e 7 a $12 \%$ de Ca) e termofosfato (18\% de $\mathrm{P}_{2} \mathrm{O}_{5}, 9 \%$ de $\mathrm{Mg}$ - Magnésio, $20 \%$ de $\mathrm{Ca}$ e $25 \%$ de $\mathrm{SiO}_{4}$ ). Porém o teor de $\mathrm{P}_{2} \mathrm{O}_{5}$ solúvel em ácido cítrico a $2 \%$ foi aproximadamente de 13,83\% na BF. Esses teores indicam que a BF tem bom potencial como fonte de $\mathrm{P}$ para a nutrição vegetal.

\subsection{Cultivo e identificação de microrganismos}


Foram obtidas 87 culturas puras de um total de 96 culturas mistas de bactérias. Das culturas puras, 63 apresentaram adaptação ao processo de criopreservação. Foram sequenciadas 58 estirpes dentre os quais apenas 48 apresentaram resultado satisfatório. As bactérias do gênero Acidocella se apresentaram em maior número dentre as estirpes identificadas, mas também foram identificadas Achromobacteria, Bacillus, Burkholderia, Fictibacillus, Halothiobacillus, Pandoraea e Thiomonas. De acordo com a análise filogenética, as estirpes de Acidocella obtidas formaram um agrupamento monofilético, enquanto que as demais estirpes de Halothiobacillus, Bacillus, Burkholderia e Achromobacteria se agruparam em ramos distintos da árvore, demostrando que são filogeneticamente distintos.

Os isolados selecionados, B1, B2 e B3, os quais foram registrados na Coleção de Culturas de Microrganismos Multifuncionais da Embrapa Milho e Sorgo, foram identificadas como bactérias pertencentes ao gênero Acidocella, com exceção da estirpe B2, que não apresentou resultado satisfatório no processo de sequenciamento de DNA. Porém, através de técnicas de genotipagem, como PCR BOX, foi evidenciado que as estirpes B1 e B2 possuem o mesmo padrão de bandas, podendo pertencer ao mesmo gênero.

Segundo Servín-Garcidueñas et al. (2013), este gênero compreende bactérias aeróbias, acidófilas, Gram-negativas pertencentes à classe Alphaproteobacteria. Os membros do gênero Acidocella foram identificados em ambientes de drenagem ácida de minas naturais que exibem altos níveis de metais pesados. Acidocella também foi detectada entre a microbiota de musgo de Sphagnum que cresce em condições acidificadas variadas. No entanto, existe pouco conhecimento sobre esse grupo de microrganismos e não há relatos na literatura de que bactérias pertencentes a este gênero sejam solubilizadoras de fósforo. Todas as espécies deste gênero foram isoladas de ambientes extremamente ácidos e apresentaram tolerância a altas concentrações de metais, como alumínio $(\mathrm{Al})$ e ferro $(\mathrm{Fe})$.

\subsection{Biossolubilização de P in vitro}

O bioensaio para solubilização de fósforo demonstrou que houve a solubilização de $\mathrm{P}$ e de outros nutrientes como o potássio $(\mathrm{K})$, magnésio $(\mathrm{Mg})$, enxofre $(\mathrm{S})$ e zinco $(\mathrm{Zn})$, todos estes elementos são importantes para a nutrição e desenvolvimento vegetal (Tabela 1). Porém, a estirpe B3, identificada pela ferramenta BLASTn como Acidocella, do filo Alphaproteobactéria, apresentou diferença significativa para a solubilização de $\mathrm{P}$ em 
relação ao controle, liberando $28 \%$ a mais de P (Figura 1), evidenciando o desempenho desta bactéria na solubilização de fosfato.

As bactérias das estirpes B1 (Acidocella) e B2 (não identificada), apresentaram melhor desempenho para a solubilização de magnésio e enxofre, na presença de enxofre elementar, em relação à bactéria correspondente à estirpe B3.

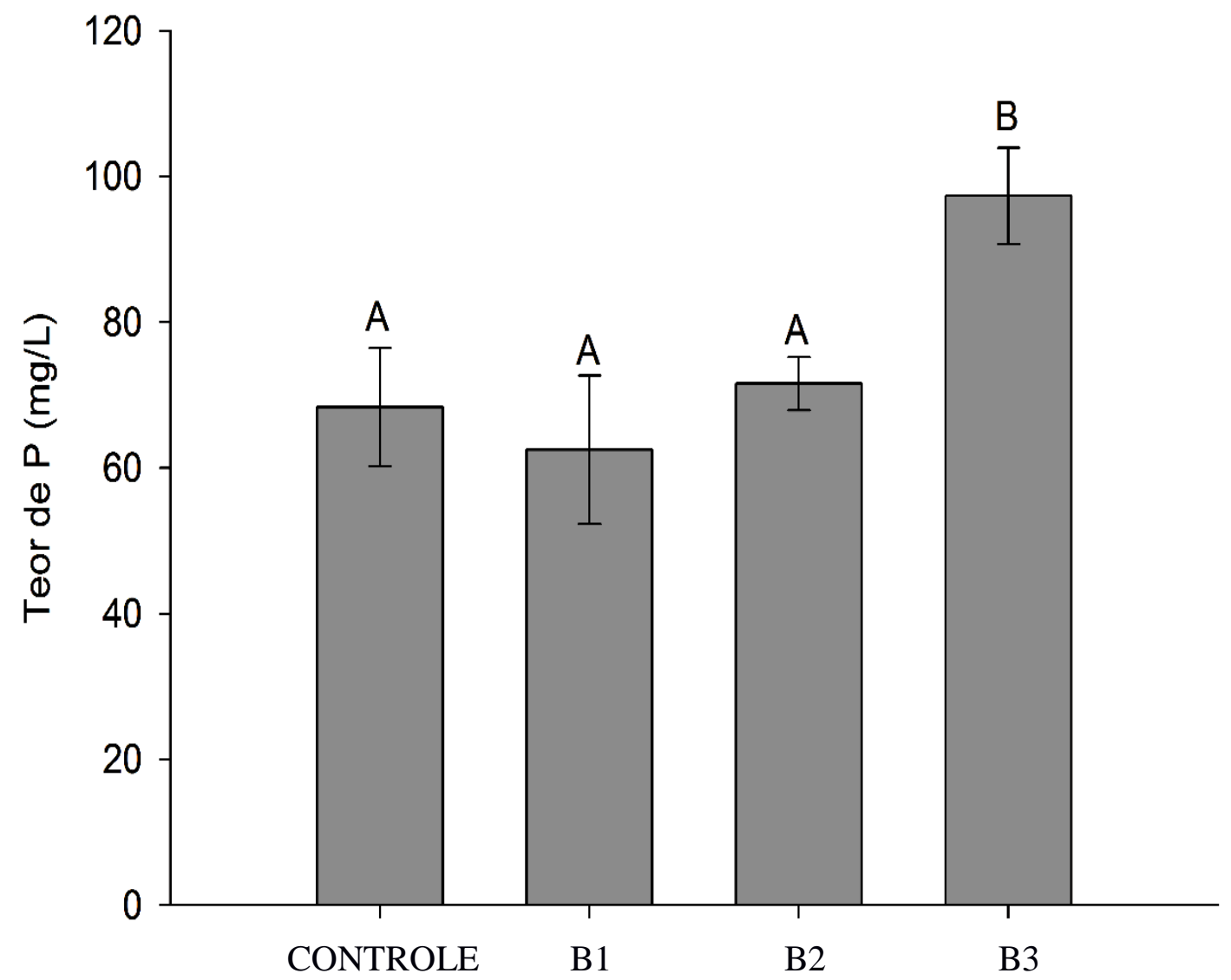

Figura 1 - Média dos teores de fósforo (P) liberado ao final de 20 dias, em meio de cultura líquido contendo borra de fosfato como única fonte de $\mathrm{P}$ ( \pm Erro Padrão da média de 3 repetições) $(\mathrm{mg} / \mathrm{L})$ contendo estirpes de bactérias acidófilas (B1, B2, B3) e o controle, sem adição de microrganismos.

*Barras seguidas de mesma letra não diferem entre si pelo teste de Tukey $(\alpha=0,05)$.

A estirpe B3 apresentou, ainda, melhor solubilização de K na presença de enxofre em relação às demais estirpes, demonstrando a capacidade de solubilização de diferentes compostos (Tabela 1). As bactérias das estirpes B1 (Acidocella) e B2 (não identificada), apresentaram melhor desempenho para a solubilização de magnésio e enxofre, na presença de enxofre elementar, em relação à bactéria correspondente à estirpe B3. 
Tabela 1 - Teores médios de potássio $(\mathrm{K})$, magnésio $(\mathrm{Mg})$, enxofre $(\mathrm{S})$ e zinco $(\mathrm{Zn})(\mathrm{mg} / \mathrm{L})$ após incubação da BF com estirpes de bactérias acidófilas (CMPC1123, CPMC1115, CPMC1109) na presença e ausência de enxofre $(S)$.

\begin{tabular}{|c|c|c|c|c|}
\hline Nutriente & Estirpe & & & \\
\hline \multirow{6}{*}{ K } & & Presença & Ausência & Média \\
\hline & Controle & $111,83 \mathrm{~B}$ & $97,87 \mathrm{C}$ & $104,85 \mathrm{C}$ \\
\hline & B1 & $115,87 \mathrm{Ba}$ & $112,17 \mathrm{Ba}$ & $114,02 \mathrm{~B}$ \\
\hline & B2 & $111,87 \mathrm{Ba}$ & $112,87 \mathrm{Ba}$ & $112,37 \mathrm{~B}$ \\
\hline & B3 & $138,63 \mathrm{Aa}$ & $129,77 \mathrm{Ab}$ & $134,20 \mathrm{~A}$ \\
\hline & Média & $119,55 \mathrm{a}$ & $113,17 \mathrm{~b}$ & \\
\hline \multirow{5}{*}{$\mathrm{Mg}$} & Controle & $137,70 \mathrm{Aa}$ & $119,47 \mathrm{Bb}$ & $128,59 \mathrm{~B}$ \\
\hline & B1 & $138,97 \mathrm{Aa}$ & $138,93 \mathrm{Aa}$ & $138,95 \mathrm{~A}$ \\
\hline & B2 & $141,37 \mathrm{Aa}$ & $147,17 \mathrm{Aa}$ & $144,27 \mathrm{~A}$ \\
\hline & B3 & $132,97 \mathrm{Aa}$ & $126,83 \mathrm{Ba}$ & $129,90 \mathrm{~B}$ \\
\hline & Média & $137,75 \mathrm{a}$ & $133,10 \mathrm{~b}$ & \\
\hline \multirow{5}{*}{ S } & Controle & $1028,33 \mathrm{Ba}$ & $864,43 \mathrm{Cb}$ & $946,38 \mathrm{C}$ \\
\hline & B1 & $1161,33 \mathrm{Aa}$ & $1156,00 \mathrm{Aa}$ & $1158,67 \mathrm{~A}$ \\
\hline & B2 & $1183,67 \mathrm{Aa}$ & $1231,33 \mathrm{Aa}$ & $1207,50 \mathrm{~A}$ \\
\hline & B3 & $1059,33 \mathrm{Ba}$ & $985,03 \mathrm{Bb}$ & $1022,18 \mathrm{~B}$ \\
\hline & Média & $1108,17 \mathrm{a}$ & $1059,20 \mathrm{~b}$ & \\
\hline \multirow{5}{*}{$\mathrm{Zn}$} & Controle & $60,36 \mathrm{Aa}$ & $40,99 \mathrm{Cb}$ & $50,68 \mathrm{~B}$ \\
\hline & B1 & $58,36 \mathrm{Aa}$ & $49,01 \mathrm{BCa}$ & $53,69 \mathrm{~B}$ \\
\hline & B2 & $60,69 \mathrm{Aa}$ & $58,93 \mathrm{ABa}$ & $59,81 \mathrm{AB}$ \\
\hline & B3 & $62,64 \mathrm{Aa}$ & $72,32 \mathrm{Aa}$ & $67,48 \mathrm{~A}$ \\
\hline & Média & $60,51 \mathrm{a}$ & $55,31 \mathrm{a}$ & \\
\hline
\end{tabular}

*Estão apresentados na tabela apenas variáveis que apresentaram interação significativa na ANOVA. Médias seguidas de mesma letra maiúscula entre colunas e minúscula entre linhas não diferem entre si pelo teste de Tukey à 5\% de probabilidade.

A estirpe B3 apresentou, ainda, melhor solubilização de K na presença de enxofre em relação às demais estirpes, demonstrando a capacidade de solubilização de diferentes compostos (Tabela 1). A B3 apresenta também resultado a solubilização de $\mathrm{Mg}, \mathrm{Zn}$ e S, elementos essenciais para o desenvolvimento de plantas. Esses resultados demonstram o potencial da biosolubilização de nutrientes contidos na BF pela ação desta estirpe. 


\section{CONCLUSÕES/RECOMENDAÇÕES}

A BF analisada apresentou alto teor de $\mathrm{P}$ com 46,72 e 13,83\% de $\mathrm{P}_{2} \mathrm{O}_{5}$ total e $\mathrm{P}_{2} \mathrm{O}_{5}$ solúvel em ácido cítrico a $2 \%$, respectivamente e teores de metais pesados dentro do limite de tolerância estabelecidos pela Instrução Normativa $\mathrm{n}^{\circ} 27$ de 5 de junho de 2006 do Ministério da Agricultura e Pecuária.

A estratégia de enriquecimento de amostras de mangue com enxofre elementar seguido de diluição e plaqueamento em meios seletivos resultou no isolamento de bactérias acidófilas, dos gêneros Acidocella, Achromobacteria, Bacillus firmus, Burkholderia, Fictibacillus, Halothiobacillus, Pandoraea e Thiomonas.

A solubilização de fósforo pela estirpe B3 resultou no aumento em 28,6\% de $\mathrm{P}_{2} \mathrm{O}_{5}$ contido no resíduo borra de fosfato em relação ao controle, bem como os teores de $\mathrm{K}$.

Esses resultados são promissores para emprego direto da BF ou após seu tratamento com bactérias solubilizadoras, principalmente após a otimização do processo de biosolubilização incluindo novos isolados de microrganismos.

\section{REFERÊNCIAS BIBLIOGRÁFICAS}

OCDE-FAO, Food and Agriculture Organization of the United Nations. Perspectivas Agrícolas 2015-2017, 2015.

PIRES, A.M.M.; MATTIAZZO, M.E. Circular técnica: Avaliação da viabilidade do uso de resíduos na agricultura. EMBRAPA, 2008.

GIFFONI, P. O.; LANGE, L. C. A utilização de borra de fosfato como matéria-prima alternativa para a fabricação de tijolos. Engenharia Sanitária e Ambiental. v. 10, n. 2, 2005.

SIMAS, R. Monitoramento da concentração e caracterização do material particulado suspenso na atmosfera. Dissertação de Pós-graduação - Universidade Federal do Paraná, 2007.

HAWKES, R. B. et al. Ferroplasma cupricumulans sp. nov., a novel moderately thermophilic, acidophilic archaeon isolated from an industrial-scale chalcocite bioleach heap. National Center for Biotechnology Information. v. 10, n. 6, 2006.

GADD, G. M. Metals, minerals and microbes: geomicrobiology and bioremediation. Microbiology, v. 156, n. 3, 2010. 
KIYAN, T. S. Técnicas básicas de lavagem e esterilização de materiais para cultura de células. Instituto de Pesquisas Energéticas e Nucleares, Departamento de Aplicações em Ciências Biológicas. ISSN 0101 3084. 1990.

STAROSVETSKY, J.; ZUKERMAN, U.; ARMON, R. H. A simple medium modification for isolation, growth and enumeration of Acidithiobacillus thiooxidans (syn. Thiobacillus thiooxidans) from water samples. Journal of Microbiological Methods, v. 92, 2013. 